\title{
Modelling of Temperature Distribution in Refractory Ladle Lining for Steelmaking
}

\author{
Olena VOLKOVA and Dieter JANKE \\ Institute of Iron and Steel Technology, Freiberg University of Mining and Technology, D-09596 Freiberg, Germany.
}

(Received on October 16, 2002; accepted in final form on March 9, 2003)

\begin{abstract}
As a first step towards optimisation of ladle treatment work, mathematical modelling of heat transfer in the ladle has been undertaken. A numerical model considering heat transfer is developed which can be used for prediction of the ladle lining temperature fields during steel casting sequences depending on wear rates and used lining materials. The model is based on Fourier differential equations. In the cases of dolomite brick, the calculational results are compared with temperature measurements from earlier publications for the periods of charged ladle, teeming, empty state and preheating whereby a good agreement is found.
\end{abstract}

KEY WORDS: thermal model; distribution of temperature; spinel mass; refractory; steelmaking ladle.

\section{Introduction}

Secondary treatment and casting ladles play a substantial role in steelmaking. Initially ladles were used exclusively as transfer vessels. At present, they serve as versatile steel reactors where homogenisation, deoxidation, desulphurisation and alloying are carried out. Close control of steel bath temperature and temperature distribution in the ladle lining is essential in order to improve both productivity and product quality. If the thermal models are intended to be used for process control in the ladle they have to be simple. Moreover, they serve to optimise ladle treatment work. Modelling is especially important to determine the choice of ladle lining materials and ladle lining dimensions. The purpose of this study is to develop a thermal model for secondary treatment and casting ladles which can be used for prediction of the ladle lining temperature fields during sequences depending on wear rates and used lining material.

\section{Theoretical Basis of Thermal Ladle Model}

\subsection{Previous Models}

Several models describing the heat conditions in ladles have been reported in the past. ${ }^{1-6)}$ According to the basic equations, these models can be arranged in four groups which comprise

- thermal models based on the equations of stationary thermal conduction ${ }^{1)}$

- thermal models based on the equations of non-stationary thermal conduction with constant inner ladle lining temperature for charged ladles, ${ }^{2-4)}$ taking into consideration first order boundary conditions

- thermal models based on the equations of non-stationary thermal conduction with free convection from the steel bath to the inner ladle lining, ${ }^{5)}$ taking into consideration third order boundary conditions

- thermal models based on the experimental analytical equations $^{6)}$

The present model has been developed in two stages. In the first place, a model based on the equations of stationary thermal conduction is developed, followed by a second model based on the equations of non-stationary thermal conduction applying first and third order boundary conditions for charged ladles.

\subsection{Stages of Heat Transfer in the Ladle}

In view of the mathematical thermal model, the ladle work is subdivided into different working periods

- preheating of the ladle after relining (16 to $72 \mathrm{~h}$ )

- break between preheating and charged state $(10 \mathrm{~min})$

- period of charged ladle (120 min)

- teeming (45 min)

- empty state (30 min)

- intermediate preheating $(60 \mathrm{~min})$.

Heat transfer in the ladle takes place in different ways depending on the stages of the process with respect to the following periods:

- Preheating and intermediate preheating of the empty ladle consisting of

- heat transfer by radiation and convection from the flue gas to the inner ladle lining

- non-stationary thermal conduction in the ladle lining

- heat transfer by radiation from the steel shell to the environment

- Break between preheating and charged ladle and during the empty state phase consisting of

- non-stationary thermal conduction in the ladle lining

- heat transfer by radiation from the steel shell to the environment

- heat transfer by radiation from the inner ladle lining to 
the environment

- Ladle filling consisting of

- heat transfer by radiation from the steel bath to the inner ladle lining

- heat transfer by natural convection from the steel bath to the inner ladle lining

- non-stationary thermal conduction in the ladle lining

- heat transfer by radiation from the steel bath to the environment

- Periods of charged ladle and ladle teeming

- heat transfer by natural convection from the steel bath to the inner ladle lining

- non-stationary thermal conduction in the ladle lining

- heat transfer by radiation from the steel shell to the environment

- natural convection in the steel bath

- heat transfer by natural convection from the steel bath to the slag

- non-stationary thermal conduction in the slag

- heat transfer by radiation from the slag to the environment

\subsection{Assumptions}

It is impossible to consider all relevant heat transfer conditions. The following assumptions have been made in the present thermal model:

- There exist no local temperature gradients in the steel bath, $T_{\mathrm{st}}=f(t)$, i.e., the steel bath is completely mixed.

- In the ladle wall, heat flow occurs only in radial direction (wall height $\gg$ wall thickness).

- In the ladle bottom and the slag, heat flow occurs only in axial direction.

\subsection{Ladle Lining}

The ladle lining consists of inner lining, back lining, insulating lining and steel shell, Fig. 1.

There exist two different types of inner linings. The first employs bricks of dolomite in the working zone and of $\mathrm{MgO}-\mathrm{C}$ in the slag zone. The second is based on castables, that is, monolithic linings from high-alumina mass with spinel addition (spinel mass) in the working zone. The important difference between spinel mass and dolomite bricks lining is determined by the mode of ladle preheating after relining. The ladle lining from dolomite brick can be preheated with constant natural gas consumption of $225 \mathrm{~m}^{3} / \mathrm{h}$. This type of preheating is also called preheating with constant heat supply. Two heating periods are distinguished:

- the first period when the flue gas temperature increases with time $\left(T_{\mathrm{fg}}=f(t)\right)$

- the second period when the flue gas temperature is con$\operatorname{stant}\left(T_{\mathrm{fg}}=\right.$ const $)$.

By this type of preheating the ladle lining from dolomite brick reaches the stationary state just after $25 \mathrm{~h}$.

Spinel mass holds a lot of humidity. For that reason, this lining must be preheated in a special preheating regime, Fig. 2, that features a long period at low temperature $\left(\approx 100^{\circ} \mathrm{C}\right)$ in order to achieve drying.

The difference between spinel mass and dolomite bricks consists not only in their shape but also in their thermal properties, as can be seen from the data in Table 1.

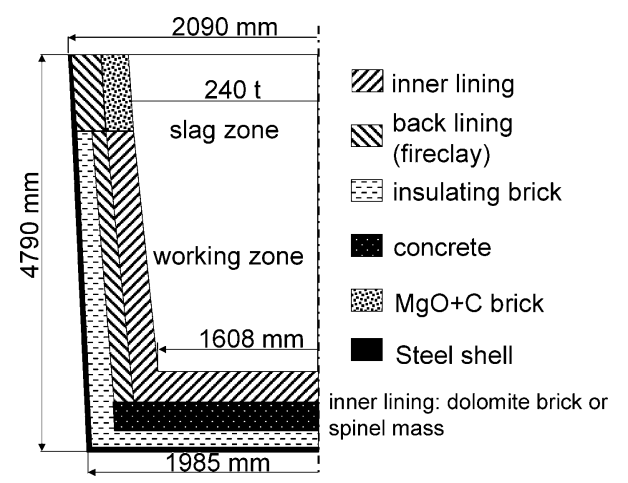

Fig. 1. Scheme of the ladle lining.

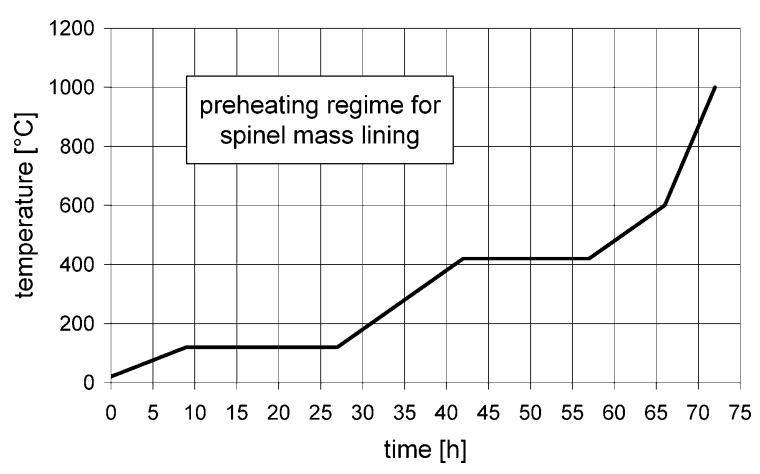

Fig. 2. Inner lining temperature in a special preheating regime for a ladle lined with spinel mass.

\section{Thermal Ladle Model Based on Stationary Thermal Conductions}

In the stationary thermal state of the ladle lining, the heat flux is constant over the distance from the inner ladle wall. This means, that

- the input heat flux to the inner ladle wall is the same as the output heat flux from the steel shell to the environment

- the ladle lining accepts no heat.

The stationary conduction is based on the Fourier's law, Fig. 3. The stationary state is found in the ladle lining, when for example

- the steel melt is remains in the ladle over an extended period

- the ladle is exposed to the preheating or intermediate preheating over an extended period.

The stationary thermal ladle model can be used for calculations and predictions of temperature distribution in the ladle lining at the end of the charged state. But the temperature distribution during the charge as function of time cannot be calculated from the stationary thermal ladle model.

The lining wear occurs mainly during of charged state. For the unproblematic ladle work, it is important to know the residual inner lining thickness. This residual inner lining thickness can be predicted quickly and simply from the steel shell temperature at the end of the charged state from the stationary thermal ladle model, Fig. 4.

The thermal ladle model is simple and the calculation time to obtain the results is shorter than in the case of nonstationary thermal conduction. The disadvantage of this model is that it assumes the simple idealized case of sta- 
ISIJ International, Vol. 43 (2003), No. 8

Table 1. Thermal properties of the lining materials depending on temperature.

\begin{tabular}{|c|c|c|c|c|c|}
\hline $\begin{array}{c}\text { refractory material } \\
{[\text { mass } \%]}\end{array}$ & \multicolumn{2}{|c|}{$\begin{array}{l}\text { thermal conductivity } \\
\qquad[\mathrm{W} / \mathrm{K} \cdot \mathrm{m}]\end{array}$} & \multicolumn{2}{|c|}{ heat capacity $[\mathrm{J} / \mathrm{K} \cdot \mathrm{kg}]$} & $\begin{array}{l}\text { density } \\
{\left[\mathrm{kg} / \mathrm{m}^{3}\right]}\end{array}$ \\
\hline high-alumina mass with spinel addition (spinel & $20^{\circ} \mathrm{C}$ & $7.5^{7)}$ & $20^{\circ} \mathrm{C}$ & $755^{7)}$ & \multirow[t]{4}{*}{$3060^{7)}$} \\
\hline mass) & $450^{\circ} \mathrm{C}$ & $4.5^{7)}$ & $500^{\circ} \mathrm{C}$ & $1165^{7)}$ & \\
\hline \multirow[t]{2}{*}{$95 \% \mathrm{Al}_{2} \mathrm{O}_{3}, 2.5 \% \mathrm{MgO} \quad 2.1 \% \mathrm{CaO}, 0.1 \% \mathrm{SiO}_{2}$} & \multirow[t]{2}{*}{$1300^{\circ} \mathrm{C}$} & \multirow[t]{2}{*}{$5^{7)}$} & $1000^{\circ} \mathrm{C}$ & $1255^{7)}$ & \\
\hline & & & $1200^{\circ} \mathrm{C}$ & $1285^{7)}$ & \\
\hline $\begin{array}{l}\text { dolomite brick } \\
38.5 \% \mathrm{MgO}, 0.6 \% \mathrm{Al}_{2} \mathrm{O}_{3} 0.8 \% \mathrm{Fe}_{2} \mathrm{O}_{3}, 59 \% \mathrm{CaO} \text {, } \\
1 \% \mathrm{ZrO}_{2}\end{array}$ & \multicolumn{2}{|c|}{$4.0^{8)}$} & \multicolumn{2}{|c|}{$1030^{8)}$} & $2860^{8)}$ \\
\hline \multirow{5}{*}{$\begin{array}{l}\text { fireclay } \\
40 \% \mathrm{Al}_{2} \mathrm{O}_{3}, 50 \% \mathrm{SiO}_{2}, 1 \% \mathrm{Fe}_{2} \mathrm{O}_{3}\end{array}$} & \multirow{5}{*}{\multicolumn{2}{|c|}{$1,4^{8)}$}} & $20^{\circ} \mathrm{C}$ & $900^{9)}$ & $2200-2300^{8)}$ \\
\hline & & & $400^{\circ} \mathrm{C}$ & $960^{9)}$ & \\
\hline & & & $600^{\circ} \mathrm{C}$ & $1000^{9)}$ & \\
\hline & & & $800^{\circ} \mathrm{C}$ & $1030^{9)}$ & \\
\hline & & & $1000^{\circ} \mathrm{C}$ & $1040^{9)}$ & \\
\hline \multirow[t]{4}{*}{ insulating brick } & $600^{\circ} \mathrm{C}$ & $0,38^{10)}$ & \multirow{4}{*}{\multicolumn{2}{|c|}{1500}} & $800-900^{10)}$ \\
\hline & $800^{\circ} \mathrm{C}$ & $0,41^{10)}$ & & & \\
\hline & $1000^{\circ} \mathrm{C}$ & $0,44^{10)}$ & & & \\
\hline & $1200^{\circ} \mathrm{C}$ & $0,48^{10)}$ & & & \\
\hline
\end{tabular}

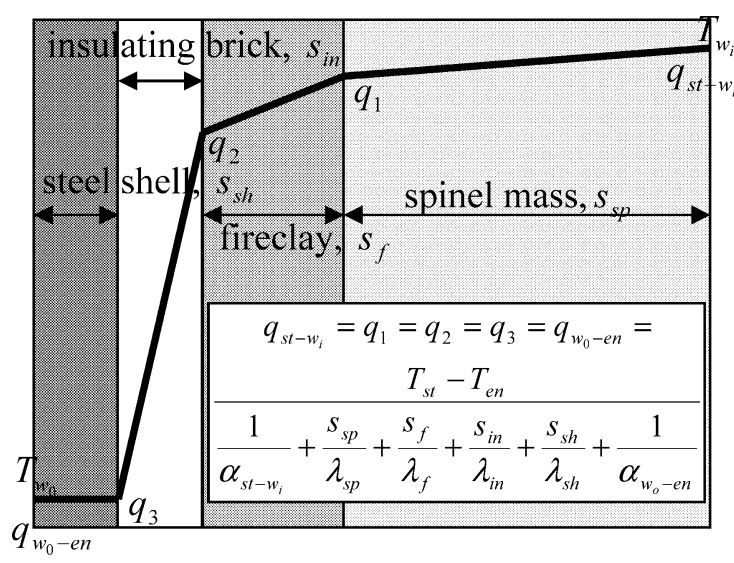

Fig. 3. Scheme of stationary thermal ladle model.

tionary conduction. The real heat flux distribution in the ladle lining changes with the time and coordinate, and cannot be completely described by stationary thermal conduction. This is the reason why a further thermal ladle model based on non-stationary thermal conduction has been developed.

\section{Thermal Ladle Model Based on Non-stationary Thermal Conduction}

The non-stationary thermal ladle model has been developed using the following boundary conditions

- constant inner ladle lining temperature for the charged state taking into consideration first order boundary conditions (named Model A)

$$
\left.T_{\mathrm{w}}\right|_{r=0}=T_{\mathrm{st}}
$$

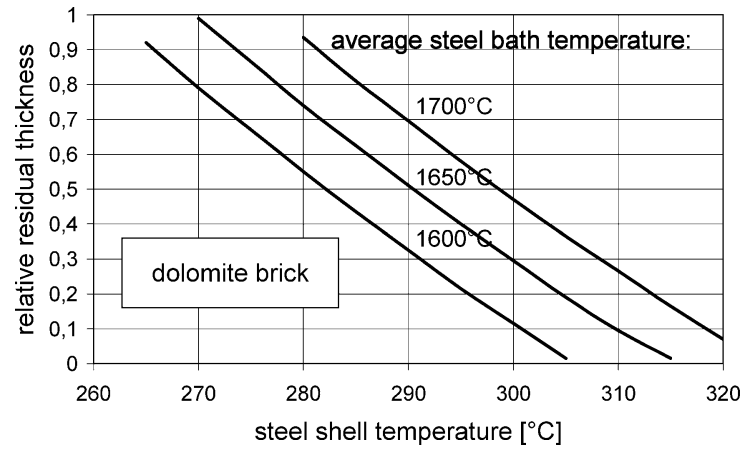

Fig. 4. Relative residual inner lining thickness of the dolomite brick wall as a function of steel shell temperature and average steel bath temperature (model calculation).

- free convection from the steel bath to the inner ladle lining in the charged state taking into consideration third order boundary conditions (named Model B)

$$
-\left.\lambda_{\mathrm{w}}\left(T_{\mathrm{w}}\right) \cdot \frac{\partial T_{\mathrm{w}}}{\partial r}\right|_{r=0}=\alpha_{\mathrm{st}-\mathrm{w}} \cdot\left(T_{\mathrm{st}}-T_{\mathrm{w}}\right)
$$

where $\alpha_{\text {st-w }}$ represents the heat transfer coefficient from the steel bath to the inner lining wall $\left[\mathrm{W} / \mathrm{m}^{2} \mathrm{~K}\right]$.

The A and B thermal ladle models are based on the differential equations for non-stationary thermal conduction.

An example of the scheme (boundary conditions) of the non-stationary thermal model is illustrated in Fig. $\mathbf{5}$ for the case of a charged ladle. In Fig. 5 the following heat flux densities are considered

- from the steel bath to the inner wall and inner bottom 


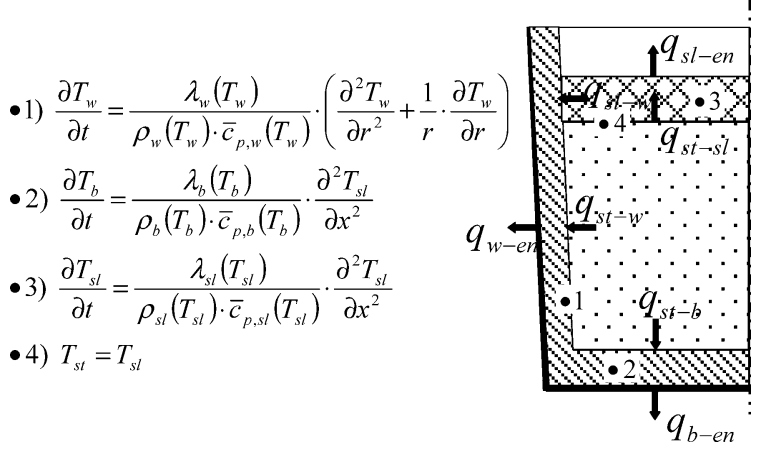

Fig. 5. Scheme of a non-stationary thermal ladle model for charged ladles (numbers 1 to 4 represent locations in the graph).

Table 2. Explanation of symbols.

\begin{tabular}{|c|c|c|}
\hline$A$ & area & $\mathrm{m}^{2}$ \\
\hline $\bar{c}_{p}$ & heat capacity & $\mathrm{J} / \mathrm{kg} \cdot \mathrm{K}$ \\
\hline$d$ & nozzle tip diameter & $\mathrm{m}$ \\
\hline$g$ & acceleration & $\mathrm{m} / \mathrm{s}^{2}$ \\
\hline$l$ & length of vertical flame & $\mathrm{m}$ \\
\hline$q$ & heat flux density & $\mathrm{W} / \mathrm{m}^{2}$ \\
\hline$Q$ & heat & $\mathrm{J}$ \\
\hline$r, x$ & coordinates & $\mathrm{m}$ \\
\hline$s$ & thickness & $\mathrm{m}$ \\
\hline$T$ & temperature & $\mathrm{K}$ \\
\hline$w$ & velocity & $\mathrm{m} / \mathrm{s}$ \\
\hline$\alpha$ & heat transfer coefficient & $\mathrm{W} /\left(\mathrm{m}^{2} \cdot \mathrm{K}\right)$ \\
\hline$\varepsilon$ & emissivity & \\
\hline$\lambda$ & heat conductivity & $\mathrm{W} /(\mathrm{m} \cdot \mathrm{K})$ \\
\hline$\rho$ & density & $\mathrm{kg} / \mathrm{m}^{3}$ \\
\hline$\sigma$ & Boltzmann constant & {$\left[\mathrm{W} / \mathrm{m}^{2} \cdot \mathrm{K}^{4}\right]$} \\
\hline$b_{i}$ & inner bottom & \\
\hline$b_{0}$ & outer bottom & \\
\hline$e n$ & environment & - \\
\hline in & insulating brick & \\
\hline$f$ & fireclay & \\
\hline$f g$ & flue gas & \\
\hline$s h$ & steel shell & \\
\hline$s l$ & slag & - \\
\hline$s p$ & spinel mass & \\
\hline st & steel bath & - \\
\hline$w_{i}$ & inner wall & \\
\hline$w_{0}$ & outer wall & \\
\hline
\end{tabular}

$$
\begin{aligned}
& q_{\mathrm{st}-\mathrm{w}}=\alpha_{\mathrm{st}-\mathrm{w}} \cdot\left(T_{\mathrm{st}}-T_{\mathrm{w}}\right) . \\
& q_{\mathrm{st}-\mathrm{b}}=\alpha_{\mathrm{st} \mathrm{b}} \cdot\left(T_{\mathrm{st}}-T_{\mathrm{b}}\right) . .
\end{aligned}
$$

- from slag to the inner lining wall (a)

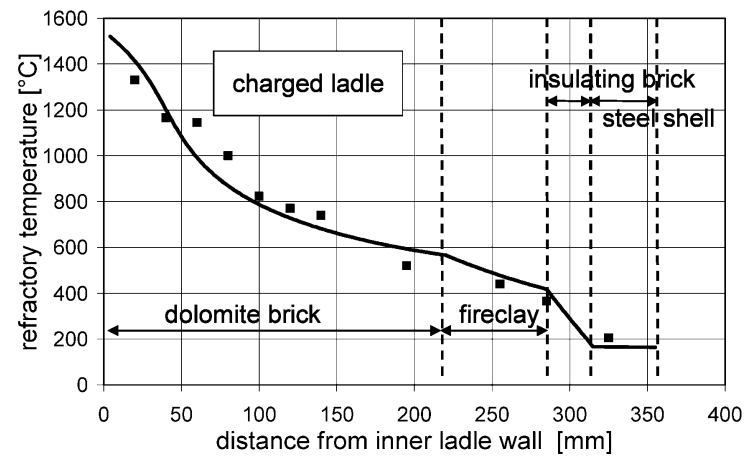

(b)

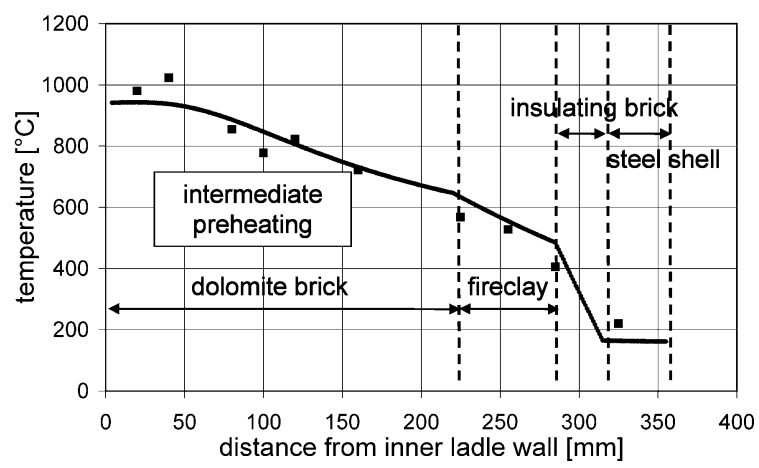

Fig. 6. Comparison of calculated (curve) with measured temperature (points) $)^{11)}$ across the ladle wall ((a) charged ladle, (b) intermediate ladle preheating).

$$
q_{\mathrm{s} 1-\mathrm{w}}=\alpha_{\mathrm{sl}-\mathrm{w}} \cdot\left(T_{\mathrm{sl}}-T_{\mathrm{w}}\right) .
$$

- from the outer wall and outer bottom to the environment

$$
\begin{aligned}
& q_{\mathrm{w}-\mathrm{en}}=\alpha_{\mathrm{w}-\mathrm{en}} \cdot\left(T_{\mathrm{w}}-T_{\mathrm{en}}\right) \\
& q_{\mathrm{b}-\mathrm{en}}=\alpha_{\mathrm{b}-\mathrm{en}} \cdot\left(T_{\mathrm{b}}-T_{\mathrm{en}}\right)
\end{aligned}
$$

- from the slag to the environment

$$
q_{\mathrm{sl}-\mathrm{en}}=\sigma \cdot \varepsilon_{\mathrm{sl}} \cdot\left(T_{\mathrm{sl}}^{4}-T_{\mathrm{en}}^{4}\right)
$$

All symbols are listed in Table 2. The solutions of the differential equations at the given boundary conditions were obtained using the Finite Difference Method explicit scheme.

The non-stationary thermal model can be used for calculations and predictions of

- natural gas combustion and length of the vertical burner flame

- ladle lining preheating and intermediate preheating

- temperature distribution for non-stationary heat transfer conditions and fixed wear rates during sequential heats

- heat losses in the ladle depending on the number of charges at given wear rates.

\section{Results and Discussion}

\subsection{Examination of Model}

The calculation of temperature distribution was made simultaneously using the models A and B. Model A was compared with temperature measurements from the literature $^{11)}$ for the cases of charged ladle, teeming, empty state and preheating period. A good agreement was found as can 


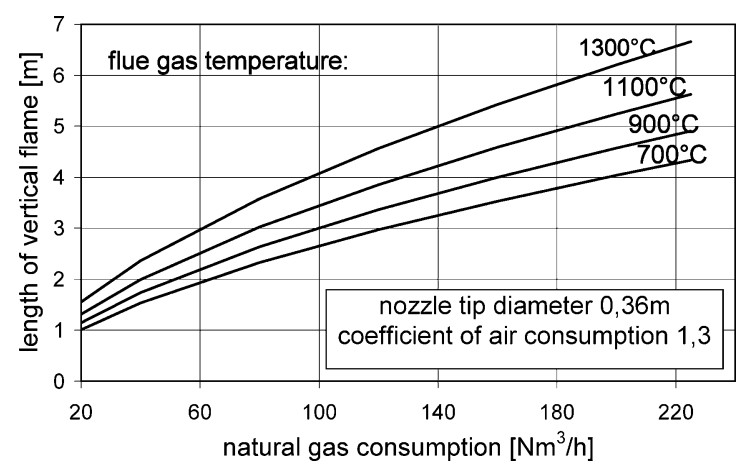

Fig. 7. Length of the vertical flame of the burner as a function of the natural gas consumption and the flue gas temperature (calculated curves)

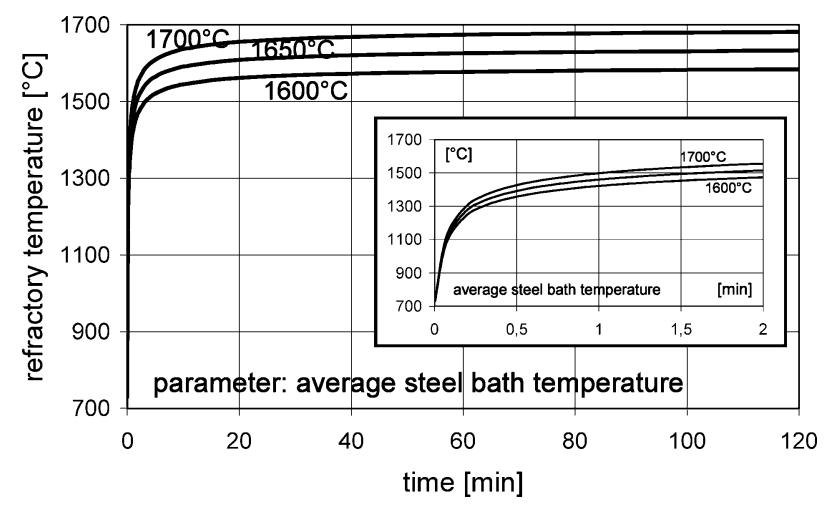

Fig. 8. Temperature of the spinel mass contact area (refractory/steel bath) as a function of time and average steel bath temperature for a charged ladle.

be seen in Fig. 6.

\subsection{Length of Vertical Burner Flame}

As already mentioned, the ladle lining preheating after relining and intermediate preheating can usually be achieved at constant gas consumption. A peculiarity of the preheating at constant gas consumption is the length change of the vertical flame. This length is defined as the region where heat transfer conditions are uniform. The length of the vertical flame is a function of the natural gas consumption, the coefficient of air consumption, the type of burner, the nozzle tip diameter and the flue gas temperature, Fig. 7. For the injection burner, the length of the vertical flame can be calculated using the following equation ${ }^{12}$

$$
l=5 \cdot d \cdot\left[\rho_{\mathrm{fg}} \cdot w^{2} /\left(\left(\rho_{0}-\rho_{\mathrm{fg}}\right) \cdot n \cdot g \cdot d\right)\right]^{0,3} \ldots
$$

where $l$, length of vertical flame $[\mathrm{m}] ; d$, nozzle tip diameter $[\mathrm{m}] ; n$, coefficient; $\rho_{\mathrm{fg}}$, density of flue gas $\left[\mathrm{kg} / \mathrm{N} \cdot \mathrm{m}^{3}\right] ; \rho_{0}$, density of the gas in the ladle at the beginning of preheating $\left[\mathrm{kg} / \mathrm{Nm}^{3}\right] ; g$, acceleration $\left[\mathrm{m} / \mathrm{s}^{2}\right] ; w$, velocity of the flue gas at the outlet of the nozzle tip $[\mathrm{m} / \mathrm{s}]$.

The increase of the vertical flame length can be one of the reasons for refractory destruction in the ladle lining bottom area.

\subsection{Inner Lining Temperature}

Figure 8 shows the temperature of the spinel mass contact area (refractory/steel bath) as a function of time for the charged ladle at different steel bath temperatures. It is obvi-

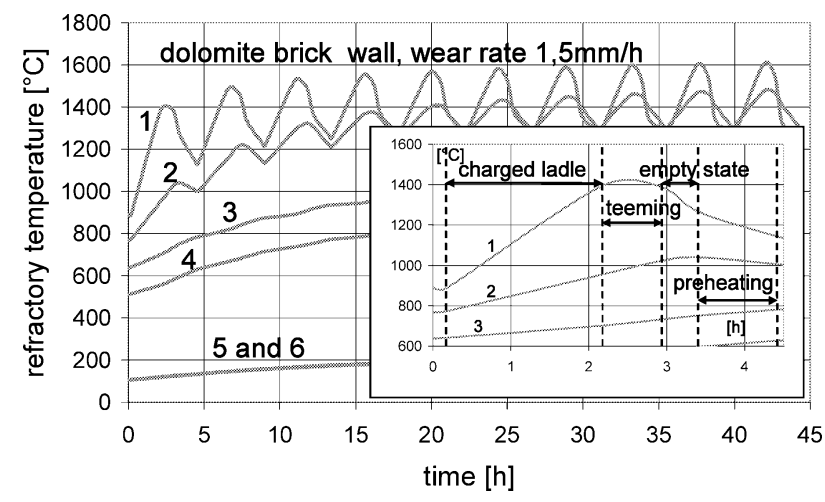

Fig. 9. Temperature fields in the ladle wall made from dolomite brick over 10 charges at a wear rate of $1.5 \mathrm{~mm} / \mathrm{h}$. Distance from inner wall: $1,50 \mathrm{~mm} ; 2,100 \mathrm{~mm} ; 3,200$ $\mathrm{mm} ; 4,265 \mathrm{~mm} ; 5,317 \mathrm{~mm} ; 6,357 \mathrm{~mm}$.

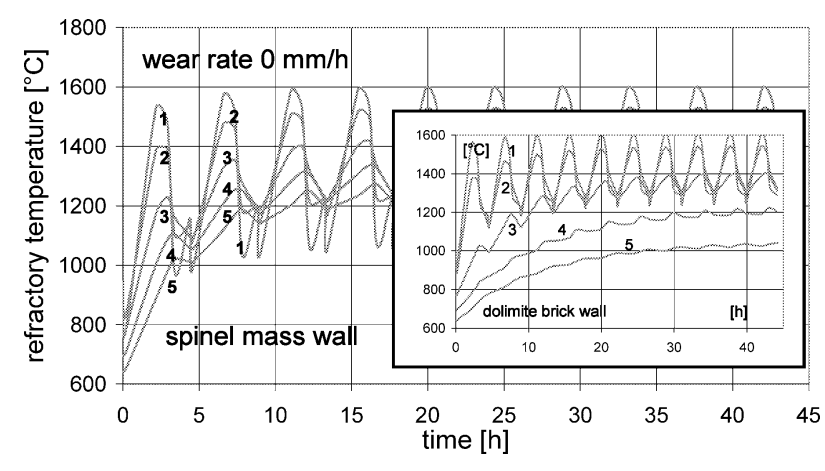

Fig. 10. Temperature fields in the ladle wall consisting of spinel mass or dolomite brick, respectively, over 10 charges at a wear rate of $0 \mathrm{~mm} / \mathrm{h}$. Distance from inner wall: 1,20 $\mathrm{mm} ; 2,50 \mathrm{~mm} ; 3,100 \mathrm{~mm} ; 4,150 \mathrm{~mm} ; 5,200 \mathrm{~mm}$.

ous that the temperature of the contact area is essentially constant when the ladle is charged. The refractory temperature changes essentially only during the first 2 min of the charged state. This implies that the assumption made in model A for boundary conditions of 1 st kind in case of the charged ladle is correct.

Figures 9 and $\mathbf{1 0}$ indicate the temperature fields of the ladle wall consisting of spinel mass and dolomite brick over 10 charges at various given wear rates. It is obvious from Fig. 9 that for ladles without wear the lining reaches the temporary stationary state after 4 to 5 charges. Figure 10 illustrates that in the case of dolomite brick lining the temperature field changes only in a lining layer of a thickness of about $100 \mathrm{~mm}$. In the case of spinel mass lining the temperature field changes in a lining layer of a thickness of $180-200 \mathrm{~mm}$. This difference is explained by the different thermal properties, especially thermal conductivity, of dolomite brick and spinel mass.

From Fig. 11 it is obvious that under the same working conditions the steel shell temperature of the ladle with spinel mass lining is higher than in the case with dolomite brick lining over 35 charges. Here the different thermal properties of dolomite brick and spinel mass exert an influence on the steel shell temperature. After 35 charges, the steel shell temperature of the dolomite brick ladle is higher than in the case of the spinell mass ladle. The reason is that the lining thickness in the case of dolomite brick is reduced stronger than in the case of spinel mass. 


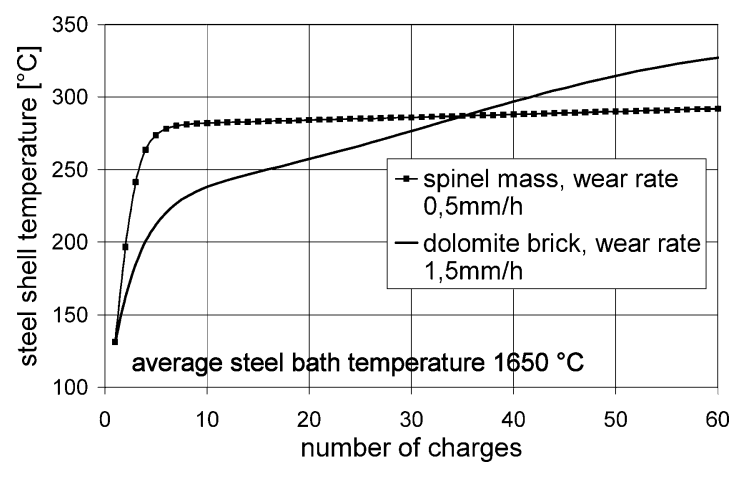

Fig. 11. Steel shell temperature at the ladle wall as a function of the charge number at an average steel bath temperature of $1650^{\circ} \mathrm{C}$ and a real wear rate of the ladle lining from dolomite brick and spinel mass.

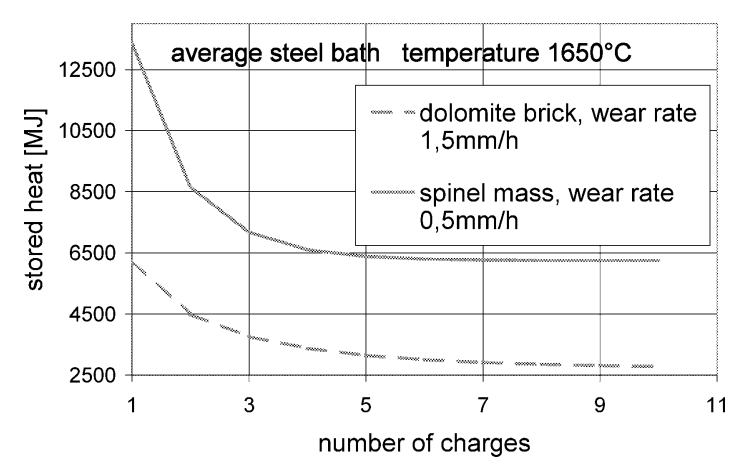

Fig. 12. Stored heat as a function of charge number at an average steel bath temperature of $1650^{\circ} \mathrm{C}$ and a real wear rate of the ladle lining from dolomite brick or spinel mass.

\subsection{Stored Heat}

Close control of the steel bath temperature is an important task for ladle operation. The loss of steel bath heat consists of

- heat loss by radiation from the steel shell to the environment

- heat accumulation in the ladle lining

- heat loss by radiation from the slag area to the environment

- heat loss by alloying and other metallurgical operations.

The stored heat in the ladle lining is dependent on the lining material, heat state and the wear and can be calculated as follows:

$$
Q=A \cdot \sum_{i} s_{i} \cdot \rho_{i} \cdot \bar{c}_{\mathrm{p}, i} \cdot\left(\bar{T}_{\mathrm{End}, i}-\bar{T}_{\mathrm{Start}, i}\right)
$$

where $Q$, stored heat $[\mathrm{J}] ; A$, lining area $\left[\mathrm{m}^{2}\right] ; l$, layer number; $\bar{T}$, average temperature $[\mathrm{K}]$.

Because of the different thermal properties, temperature distribution and higher real wear rate of the dolomite, the stored heat in the spinel mass lining differs from that in the dolomite brick one. Figure 12 illustrates the stored heat in the ladle lining from spinel mass and dolomite brick, respectively, in the case of wear rates which have been observed in practice. From these figures it is obvious that a maximal heat accumulation is observed during the first 1 to 4 charges. The degree of heat accumulation depends on the ladle preheating. An improved ladle lining preheating results in less heat accumulated. After 4 to 5 charges, the accumulated heat is constant during the ladle campaign.

From the data in Fig. 12 it is concluded that the temperature loss of the steel bath in the ladle lined with spinel mass is higher than that in the ladle lined with dolomite brick.

\section{Summary and Conclusions}

From the results the following conclusions are drawn:

(1) During preheating at constant natural gas consumption the length of the vertical burner flame increases strongly. This increase can be one of the causes for bottom destruction.

(2) In ladle operation without wear (ideal case) the lining reaches the temporary stationary state after 4 to 5 charges.

(3) For dolomite brick ladle lining, the temperature field changes only across a lining layer thickness of about $100 \mathrm{~mm}$. For spinel mass lining the temperature field changes across a lining layer thickness of 180-200 mm. The difference is explained by the different thermal properties of the lining materials, especially their thermal conductivity.

(4) The stored heat in the spinel mass lining is higher than that in the dolomite brick lining at real wear rates. This means that the temperature loss of the steel bath in the ladle lined with spinel mass is higher than that in the ladle lined with dolomite.

\section{REFERENCES}

1) K. Rieche, W. Koehn and K. Wuennenberg: Stahl Eisen, 105 (1985), No. $9,981$.

2) S. Yilmaz and H.-F. Schweiger: Stahl Eisen, 117 (1997), No. 6, 71.

3) N. N. Ivanov: Stal', (1997), No. 12, 20.

4) L. S. Steinberg, L. A. Goldberg, V. I. Kusina, V. A. Vladimirov and B. S. Tchaykin: Stal', (1995), No. 11, 14.

5) H. Pfeifer: Stahl Eisen, 117 (1997), No. 12, 115.

6) N. Bannenberg: Stahl Eisen, 114 (1994), No. 9, 77.

7) F. Simonin, C. Olagnon and G. Fantozzi: Project BE 96-3124, Technical Meeting T6, EKO Stahl, Eisen-huettenstadt, BRD., (2000).

8) G. Routschka: Taschenbuch Feuerfeste Werkstoffe, Vulkan-Verlag, Essen, (2001).

9) H. Salmang and H. Scholze: Keramik, Teil:2 Keramische Werkstoffe. Springer-Verlag, Berlin, Heidelberg, New York, Tokyo, (1983), 124.

10) Refractory Materials and Their Properties, Didier-Werke AG, Wiesbaden/Germany, (1997), 56.

11) H. Dege and A. Kuntze: Untersuchung der Temperaturveraenderung der Stahlschmelze vom Abstich bis zur Kokille, IEST TU BAF, Germany, (1985).

12) T. S. Menschikova, N. N. Ivanov and A. N. Ivanov: Stal', (2000), No. 1,16 . 